\title{
Clasificaciones de videojuegos. Una propuesta práctica para estudios empíricos
}

\author{
Laura Mejías-Climent
}
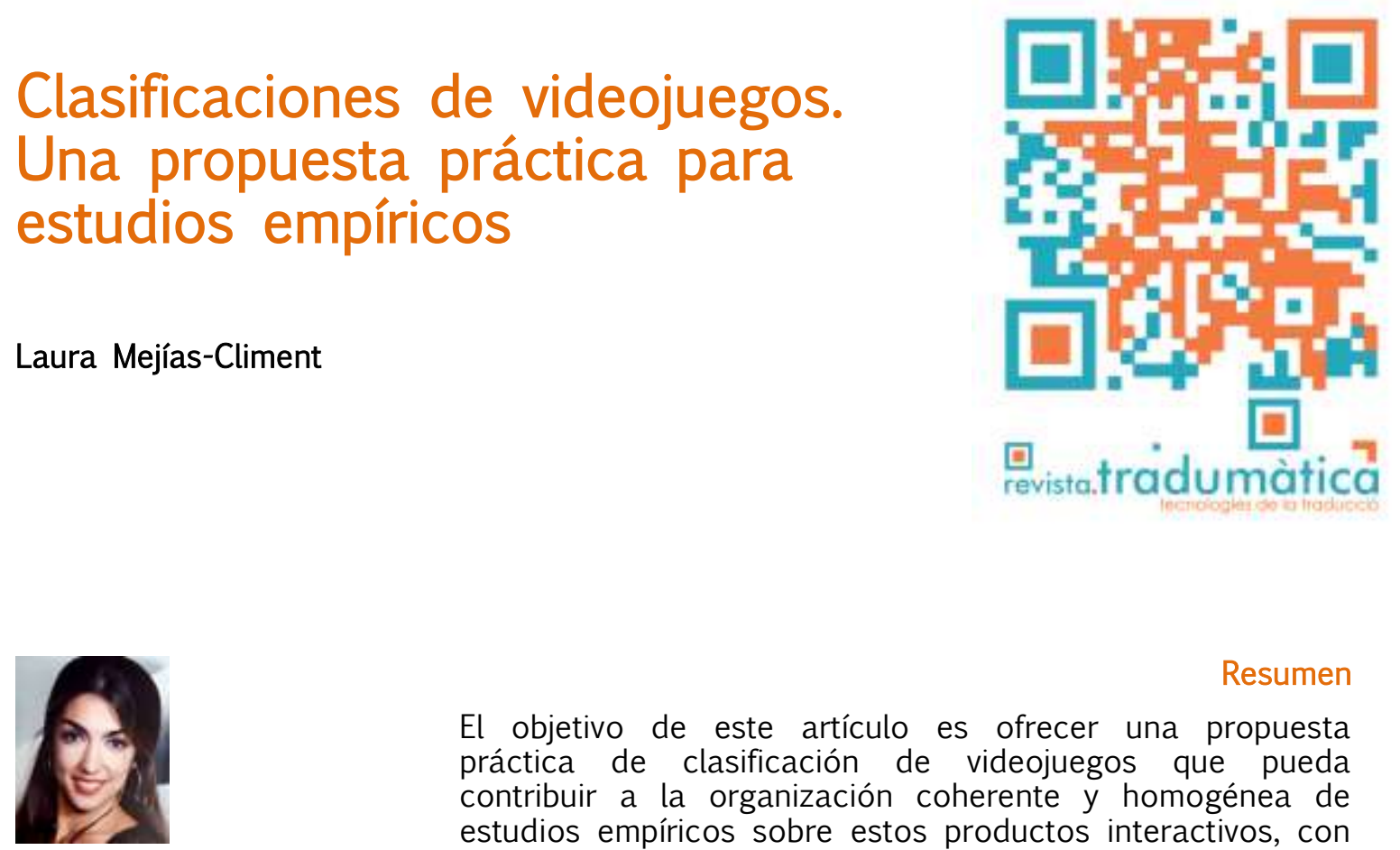

Mejías-Climent, Laura Universitat Jaume I Imejias@uji.es; ORCID: 0000-0003-2933-7195

El objetivo de este artículo es ofrecer una propuesta práctica de clasificación de videojuegos que pueda contribuir a la organización coherente y homogénea de estudios empíricos sobre estos productos interactivos, con vistas a proponer también su arraigo no solo en el plano investigador, sino también en la industria o la prensa especializada. La propuesta se fundamenta en una revisión teórica de clasificaciones previas, especialmente, del ámbito de los Game Studies y la localización, aunque también se han consultado diversas fuentes de la industria y la prensa especializada para mantener la coherencia terminológica en todos los ámbitos. Del mismo modo, se ofrece una sucinta demostración de su utilidad mediante el ejemplo de un estudio descriptivo realizado sobre el doblaje de videojuegos de acción-aventura. La clasificación propuesta consta de nueve géneros interactivos, según el criterio único de las destrezas empleadas en el juego, a saber: combate, aventura, carreras, puzles y laberintos, simulación, estrategia, ritmo, didácticos y competición y concursos; y podrá ampliarse a tantos géneros o subgéneros como tipos de juegos puedan surgir.

Palabras clave: clasificación, géneros, localización, videojuegos, estudios descriptivos en traducción

Resum

L'objectiu d'aquest article és oferir una proposta pràctica per a la classificació de videojocs que pugui contribuir a l'organització coherent i homogènia d'estudis empírics sobre aquests productes interactius, amb l'objectiu de proposarne també l'establiment no només en el pla de la recerca, sinó també en el de la indústria o el de la premsa especialitzada. La proposta es basa en una revisió teòrica de classificacions prèvies, especialment, en l'àmbit dels Game Studies i la localització, tot i que també han estat consultades diverses fonts de la indústria i la premsa especialitzada per mantenir la coherència terminològica en tots els àmbits. De la mateixa manera, oferim una demostració concisa de la seva utilitat per mitjà de l'exemple d'un estudi descriptiu realitzat sobre el doblatge de videojocs d'acció-aventura. La classificació proposada consta de nou gèneres interactius, segons el criteri únic de les habilitats utilitzades en el joc, que són: combat, aventura, curses, puzles i laberints, simulació, estratègia, 
ritme, didàctics i competició, i concursos; i podrà ampliar-se a tants gèneres o subgèneres com tipus de jocs puguin aparèixer.

Paraules clau: classificació, gèneres, localització, videojocs, estudis descriptius en traducció

\section{Abstract}

The aim of this article is to propose a practical classification of video games, which may contribute to systematizing and homogenizing empirical studies on different aspects of these interactive products, with a view to proposing its adoption not only at the research level, but also in the industry and the specialized press. This proposal is based on a theoretical analysis of previous classifications, especially, in the field of Game Studies and localization, although various industry and specialized press sources have also been consulted in order to maintain terminological consistency in all areas. Likewise, the use of this classification proposal will be briefly illustrated by a descriptive study carried out on the dubbing of action-adventure video games. The classification contains nine interactive genres, applying the single classification criterion of the types of activities required in each category, namely: combat, adventure, racing, puzzles and labyrinths, simulation, strategy, rhythm, educational, competition and contest. This proposal is open to adding as many genres or sub-genres as new video games might arise.

Keywords: classification, genres, localization, video games, descriptive translation studies

\section{Introducción}

Este artículo explorará las posibilidades de categorización que ofrece el dinámico campo de los videojuegos, una industria en continuo crecimiento que bate récords económicos cada año (Wijman, 2020). Una de las cuestiones básicas al acercarnos a este mercado es comprender cómo pueden organizarse y categorizarse los videojuegos según sus distintas características. Una taxonomía sólida y justificada podría ser de utilidad para trazar rasgos identificativos y expectativas lúdicas tanto en el plano investigador como en el ámbito cotidiano de los jugadores y de la propia industria y la prensa especializada -si bien, resulta complejo aspirar a la universalidad de una propuesta investigadora que pueda tener arraigo en la industria de los videojuegos, cuya pugna por la originalidad y la diferenciación de cada empresa es incesante.

En cualquier caso, el interés epistemológico por categorizar elementos y agruparlos según criterios compartidos, entre otras áreas, tampoco escapa a los Estudios en Traducción (ET), en donde, a través de la Lingüística, comenzaron a surgir numerosas propuestas de clasificación de textos y géneros a partir de los 60 (Jiménez-Crespo, 2013: 68). Actualmente, el ámbito de los videojuegos y, por ende, el de la localización también se prestan a la categorización de estos productos y, de hecho, la misma esencia de la localización no puede entenderse sin contemplar su relación con las distintas convenciones textuales. En los términos empleados por Nord (2018), la localización es un claro ejemplo de traducción instrumental, cuyo objetivo principal es la producción de un texto meta que el receptor consuma con plena naturalidad, como si no se tratara de un producto traducido, sino que toma como modelo el texto de partida y cumple un objetivo determinado por su categoría en la cultura meta, como si fuera la producción original. El conocimiento pleno de las convenciones del género al 
que el producto en cuestión pertenece es imprescindible, por tanto, para que quien localiza acometa con éxito su tarea (Jiménez-Crespo, 2013).

En áreas como la literatura, la música o el cine, los géneros se emplean para categorizar obras según determinados criterios estilísticos y permiten así el agrupamiento de obras similares. Las convenciones de los géneros también ofrecen a los creadores un modelo que pueden emular. Asimismo, en términos generales, uno de los objetivos esenciales de la clasificación por géneros es facilitar el almacenamiento y la recuperación, así como guiar a los consumidores en la elección de unas obras u otras, según el conocimiento tácito que se da en cada sociedad de los géneros cinematográficos, literarios o musicales. La categorización por géneros, asimismo, actúa como estrategia de marketing para las empresas y, en el plano educativo, como herramienta pedagógica para reflejar ejemplos claros que quienes estudian deben conocer y reproducir (Clarke, Lee y Clark, 2017).

En los ET en particular, los principios teóricos y metodológicos de la clasificación por géneros se emplean ampliamente para la formación y la investigación en numerosas modalidades y campos, como la traducción científico-técnica, la legal o la jurídica. Y aún no se ha reconocido suficientemente su utilidad para avanzar en la formación, la práctica y la investigación de la localización (Jiménez-Crespo, 2013: 37). Dada esta necesidad, consideramos oportuno ofrecer una propuesta de taxonomía de videojuegos, si no arraigada, al menos plenamente compatible con la industria y la prensa especializada, y que también pueda emplearse en estudios sobre las estrategias y enfoques de la localización según los rasgos particulares de cada grupo de juegos.

Aplicada específicamente a los videojuegos, la clasificación por géneros se ha enfrentado al reto del vertiginoso avance que estos productos han experimentado desde sus orígenes, hacia los años 60 (Levis, 2013). De hecho, «the emergence of new works and media, such as video games, challenge traditional genre conceptualizations and boundaries» (Clarke, Lee y Clark, 2017: 446). Esta conceptualización ha de ajustarse a un producto concreto, los videojuegos, cuyas desarrolladoras buscan la originalidad y el dinamismo continuos en la pugna por conquistar jugadores y mercados.

A pesar de su utilidad, las taxonomías en videojuegos varían enormemente según la fuente consultada y el ámbito al que esta pertenezca. Así, el objetivo de este artículo será ofrecer un análisis teórico para recuperar algunas de las categorizaciones de videojuegos que se han hecho hasta la fecha. A continuación, se ofrecerá una propuesta que pueda resultar útil y práctica para emplearse en investigación, en consonancia con la terminología de la industria. En nuestro caso, ejemplificaremos las posibilidades de uso de esta propuesta mediante la mención a un estudio empírico sobre localización que busca trazar tendencias en el doblaje de videojuegos de acción aventura, si bien, esta no es más que una de las numerosísimas posibilidades de estudio que aún ofrecen los videojuegos y su localización en particular. 


\section{Los géneros de videojuegos: Criterios de clasificación}

Según Clarke, Lee y Clark (2017: 446-447), la delimitación de los denominados "géneros» en diversos medios surge de agrupamientos en función de características identificables. Las clasificaciones por géneros buscan organizar obras según rasgos observables y objetivos, como es el caso de las etiquetas cinematográficas según convenciones estilísticas y narrativas, o las categorías musicales, determinadas por elementos como el estilo, la forma y las emociones que suscitan. Los géneros en videojuegos también agrupan características similares, pero la elección de dichos rasgos ha variado diacrónicamente. Según los mismos Clarke, Lee y Clark (2017: 448), muchas de las categorizaciones propuestas para videojuegos se fundamentan en ideas procedentes de la literatura y el cine, y así, traen consigo también los sesgos de estos ámbitos.

El punto de partida necesario para establecer una clasificación coherente es delimitar con claridad el criterio de organización empleado, de manera que no se mezclen características; «the first determining factor of any generic typology lies in the criteria it uses. In the case of video games, we have two types of criteria: those pertaining to gameplay, and those of theme or narrative» (Arsenault, 2009: 154).

A tal respecto, cabe señalar que desde los Game Studies se mantiene un continuo debate entre quienes prefieren la concepción narrativa de estudio de los videojuegos y los defensores de la corriente ludológica. Estos segundos consideran que la experiencia de juego (gameplay) es el factor preponderante para comprender el funcionamiento del videojuego. Apperley (2006: 8) y Frasca (2003) explican esta dicotomía de aproximaciones: la narratológica agrupa aquellos enfoques que se basan en paradigmas narrativos y recurren a las herramientas de la literatura y la teoría fílmica, muy probablemente debido a la inicial falta de una disciplina coherente y formal que se ocupara del estudio de los videojuegos.

Por su parte, la postura ludológica, en lugar de concebir los videojuegos a partir de estrategias narrativas o representativas, busca comprender sus estructuras y elementos, en especial, las reglas del juego, así como crear tipologías y modelos que expliquen las mecánicas de juego y la jugabilidad (Frasca, 2003: 222). Estas dos aproximaciones nos permiten apuntar ya a los dos primeros criterios para crear taxonomías de videojuegos: la experiencia interactiva que ofrecen (ludología) o la construcción narrativa que los configura (narratología).

Además de estos, en los estudios sobre clasificaciones de videojuegos aparecen otros dos criterios más: la plataforma y el modo de juego. Tales criterios emergen al considerar explícitamente los rasgos tecnológicos del entorno audiovisual (en qué aparatos se juega y qué visión se tiene) e interactivo (cuántas personas participan). Estos dos nuevos criterios, además de las citadas posiciones ludológica y narratológica, suman un total de cuatro criterios según los que pueden proponerse taxonomías de videojuegos.

Los videojuegos son un entorno expresivo que representa el funcionamiento de sistemas reales e imaginados, e invitan a los jugadores a interactuar con ellos (Bogost, 2007: vii). En esta configuración, las funciones comunicativas se apoyan también en nociones de entretenimiento, estética y diseño (Clarke, Lee y Clark, 2017: 448), que 
combinan la configuración audiovisual con la dimensión interactiva. Por ello, a la vista de todos estos factores presentes en un juego, los criterios que permiten crear categorías de videojuegos pueden girar en torno a los cuatro elementos citados, ya recogidos por Clearwater (2011) y O’Hagan (2007) como posibles criterios para clasificar videojuegos:

- La plataforma en la que se juegue, es decir, el hardware o dispositivo físico en el que se ejecute el juego: recreativas, ordenadores, consolas, consolas portátiles o teléfonos móviles.

- El modo de juego abarca dos aspectos: la perspectiva de visión (primera, tercera persona o mixta) y el uso individual o colectivo (multijugador).

- El medio (milieu o entorno), concebido desde el punto de vista literario y cinematográfico, según las convenciones tradicionales estilísticas y narrativas, temáticas e iconográficas (Wolf, 2005: 114). Según esta aproximación, el medio puede equipararse a la división de géneros audiovisuales (Hurtado, 2001/2011; Chaume, 2003; Agost, 1999). Algunos ejemplos son la comedia, la intriga, el terror...

- El género (interactivo), definido por Clearwater (2011) como el tipo de actividades y tareas que el jugador desarrolla durante el juego (rapidez, estrategia, enfrentamientos, destreza mecánica...). El criterio, por tanto, se fundamenta en el tipo de relación que se establece entre jugador y juego. En adelante, debe diferenciarse el término "género (interactivo)», en este sentido concreto de «experiencia», del género en su acepción más amplia y extendida, como grupo que comparte unas características estilísticas y estéticas comunes, como pueden ser los géneros literarios o cinematográficos. También Wolf (2005: 114) matiza esta concepción añadiendo que son géneros «interactivos» (interactive genres): «interactivity is an essential part of every game's structure and a more appropriate way of examining and defining video game genres».

Estos cuatro criterios de clasificación se han empleado durante la evolución e historia de los videojuegos $\mathrm{y}$, de hecho, «se ha constatado la tendencia creciente a combinar elementos de diferentes géneros, para que el argumento sea más variado y presente nuevos retos» (Vela Valido, 2005: 258). También la incesante evolución tecnológica obliga a ampliar y actualizar clasificaciones y, en muchas, el rasgo común es el uso combinado, consciente o inconscientemente, de varios de los criterios anteriores.

Asimismo, es natural que el punto de vista de quien propone una clasificación, o su relación con los videojuegos, influyan en optar por unos criterios u otros: mientras que, en el ámbito académico, parecen preferirse clasificaciones según el género interactivo o el medio narrativo (ludología-narratología), las empresas establecen clasificaciones según sus necesidades propias, que compiten por la originalidad y la novedad para los fans $y$, muchas veces, ofrecen categorías que se solapan y carecen de homogeneidad (Frasca, 2001: 11). Tampoco parece haber un acuerdo entre industria y academia: «formal academic work is often overlooked by creators and consumers of games» (Clarke, Lee y Clark, 2017: 447), lo que provoca una discordancia aún mayor entre taxonomías.

\subsection{Propuestas de la industria}

No es de extrañar que las desarrolladoras prefieran acostumbrar a sus jugadores a clasificaciones que combinan varios criterios, en su búsqueda continua de originalidad y 
para diferenciar su identidad comercial. Los consumidores aceptan y emplean dichas clasificaciones con naturalidad, ya que ofrecen gran cantidad de datos condensados sobre las características de los juegos que encontrarán bajo cada categoría. "After all, videogame genres are not only helpful for gamers' identity constructions but they fulfill a powerful commercial role as well» (Ensslin, 2012: 44). Son, así, categorizaciones útiles para los jugadores, creadas según el perfil de las empresas, pero poco uniformes desde un punto de vista académico. "In other words, these typologies are naïve rather than scientific» (Frasca, 2001: 11). Bermejo (2013: 32) señala la multiplicidad existente de clasificaciones y las inconsistencias que se dan frecuentemente:

Uno de los problemas que plantea el estudio crítico del videojuego es la ingente cantidad de productos que aparecen cada año para las diversas plataformas existentes. Ello dificulta una cuestión que todavía está pendiente en este campo: la clasificación genérica. [...] Debe reconocerse que el concepto de "género» nos resulta útil para «situar» y analizar una obra a partir de unos rasgos formales y de contenido. Respecto al videojuego, las clasificaciones según el sistema de juego o la temática se entremezclan: estrategia, acción, aventura gráfica, arcade, puzle, simulador deportivo, RPG, MMORPG... Y de esta "confusión» surgen solapamientos.

Tales solapamientos y la falta de uniformidad pueden comprobarse en las heterogéneas clasificaciones disponibles en línea. Mostremos el ejemplo del sitio web de Ubisoft, donde se recogen las siguientes categorías como géneros de sus videojuegos. Para comprobar, además, que se trata de categorías dinámicas, que evolucionan a la par que el medio, la tabla 1 muestra tales géneros según consultas a la web en cuatro años consecutivos (en el futuro, estas mismas categorías consultadas hasta 2020 podrán haber cambiado).

Puede observarse la evolución de las categorías consideradas «géneros» por la citada compañía. De 2019 a 2020 no han variado, aunque sí el orden en el que se presentan en la web. En cualquiera de los años, pueden identificarse combinaciones de los cuatro criterios descritos en el apartado anterior. Por ejemplo, la categoría «Shooter en tercera persona» se rige por los criterios de género interactivo (lucha) y modo (visión en tercera persona), mientras que los juegos «Arcade» se refieren a la plataforma. A pesar de ello, debe reconocerse que, al acceder a esta web, de un solo vistazo ya se dispone de mucha información sobre el tipo de juegos que pueden encontrarse: juegos centrados en destruir al enemigo mediante armas, habitualmente de fuego, desde una perspectiva externa al personaje, en el caso de los shooter en tercera persona; y juegos que se jugaban tradicionalmente en máquinas recreativas y que recuperan dicha estética, en el caso de los arcade.

Además de la evolución diacrónica de los géneros según una misma desarrolladora, pueden compararse las distintas categorías que varias empresas consideran géneros de los videojuegos que comercializan.

También las plataformas de venta no adscritas a una única desarrolladora recogen taxonomías diversas. En todas, la tendencia habitual parece ser la de distinguir entre plataformas, para las que ofrecen juegos; y géneros, bajo los cuales, como puede comprobarse en la tabla 2, se agrupan denominaciones que responden a cualquiera de los cuatro criterios anteriores, no únicamente a uno. 


\begin{tabular}{|c|c|c|c|}
\hline & \multicolumn{3}{|c|}{ Géneros en Ubisoft } \\
\hline 2017 & $\begin{array}{c}\text { FPS } \\
\text { Gestión } \\
\text { Movimiento } \\
\text { Música } \\
\text { Plataformas }\end{array}$ & $\begin{array}{l}\text { Carreras } \\
\text { Juego de rol } \\
\text { Simulación } \\
\text { Deportes } \\
\text { Estrategia }\end{array}$ & $\begin{array}{c}\text { Estrategia y cartas } \\
\text { Shooter táctico } \\
\text { Shooter } \\
\text { en tercera persona } \\
\text { Bienestar }\end{array}$ \\
\hline 2018 & $\begin{array}{c}\text { Acción/Aventura } \\
\text { Shooter } \\
\text { Simulación }\end{array}$ & $\begin{array}{c}\text { Estrategia } \\
\text { Familiar } \\
\text { Survival horror }\end{array}$ & $\begin{array}{c}\text { Carreras } \\
\text { Ubisoft Legacy }\end{array}$ \\
\hline 2019 & $\begin{array}{c}\text { Casual } \\
\text { Co-op } \\
\text { Horror } \\
\text { Puzzle [sic] }\end{array}$ & $\begin{array}{c}\text { Shooter } \\
\text { Acción/Aventura } \\
\text { Carreras } \\
\text { Estrategia }\end{array}$ & $\begin{array}{l}\text { Lucha } \\
\text { Multijugador } \\
\text { Música } \\
\text { Simulación }\end{array}$ \\
\hline 2020 & $\begin{array}{c}\text { Acción/Aventura } \\
\text { Casual } \\
\text { Co-op } \\
\text { Lucha }\end{array}$ & $\begin{array}{c}\text { Horror } \\
\text { Multijugador } \\
\text { Música } \\
\text { Puzzle [sic] }\end{array}$ & $\begin{array}{l}\text { Carreras } \\
\text { Shooter } \\
\text { Simulación } \\
\text { Estrategia }\end{array}$ \\
\hline
\end{tabular}

Tabla 1. Géneros de videojuegos en la web de Ubisoft Store Fuente:〈https://store.ubi.com/es/game-genre〉

Parecen existir casi tantas clasificaciones como entidades comerciales. En todas se mezclan criterios de clasificación. Tampoco hay uniformidad en la terminología empleada, incluso refiriéndose a un mismo concepto («Aventura» o «Aventuras», «Rol» O «Juegos de rol», «Disparos» o «Shooter», etc.). El uso de anglicismos es habitual, puesto que implica cierto atractivo para los consumidores (Scholand, 2002: 2). Asimismo, se contemplan categorías transversales, es decir, en las que podrían incluirse distintos géneros, como es el caso de los juegos «Indie» de Steam, cuyo criterio de clasificación parece responder a la consolidación y capacidad económica de la desarrolladora, aspecto que podría considerarse en cualquier género.

Además de diferencias diacrónicas en una misma empresa y diferencias entre desarrolladoras, también se dan variaciones culturales, como señalan O’Hagan y Mangiron (2013: 67), quienes citan el mayor número de géneros que existen en la cultura japonesa frente a los territorios occidentales. Veamos qué sucede en el caso de la prensa especializada y, a continuación, en el plano académico. 


\begin{tabular}{|c|c|c|c|}
\hline Steam & Origin & Nintendo & EA Games \\
\hline Género & Género & Género & Género \\
\hline Acción & Acción & Acción & Acción \\
\hline Aventura & Aventura & Aventura & Aventuras \\
\hline Carreras & MMO & Arcade & Familiar \\
\hline Casual & Puzzle [sic] & Lucha & Fantasía \\
\hline Deportes & Conducción & $\begin{array}{l}\text { Salud y forma } \\
\text { física }\end{array}$ & Terror \\
\hline Estrategia & Juego de rol & Música & Infantil \\
\hline Indie & Shooter & Fiesta & MMORPG \\
\hline Multijugador masivo & Simulación & Plataformas & Musical \\
\hline Rol & Deportes & Puzle & Puzles \\
\hline \multirow[t]{6}{*}{ Simuladores } & Estrategia & Carreras & Conducción \\
\hline & & Rol (RPG) & $\begin{array}{c}\text { Juegos de rol } \\
\text { (RPG) }\end{array}$ \\
\hline & & Disparos (shooter) & Disparos \\
\hline & & Simulación & Simulación \\
\hline & & Deportes & Deportivos \\
\hline & & Estrategia & Estrategia \\
\hline
\end{tabular}

Tabla 2. Clasificaciones comerciales en cuatro distribuidoras de videojuegos en 2020

\subsection{Propuestas de la prensa especializada}

Al igual que ocurre con las propias desarrolladoras y distribuidoras, la prensa especializada no escapa a la heterogeneidad de clasificaciones. Este hecho puede ilustrarse en la tabla 3, que recoge las distintas clasificaciones que ofrecen en sus webs, en 2020, cuatro de los más populares medios informativos sobre videojuegos de nuestro país (López Redondo y Aramburú Moncada, 2020: 23-25). 


\begin{tabular}{|c|c|c|c|}
\hline MeriStation & HobbyConsolas & Vandal & 3DJuegos \\
\hline Géneros & Género & Género & Género \\
\hline Acción & Acción & Aventura Gráfica & Acción \\
\hline Conducción & Aventura & Estrategia & Aventura \\
\hline RPG & Deportes & Musical & Casual \\
\hline Deportes & Estrategia & Plataformas & Conducción \\
\hline Estrategia & Lucha & Rol & Deportes \\
\hline Aventura gráfica & Musical & Velocidad & Estrategia \\
\hline Simulación & Otros & Acción & MMO \\
\hline Educación & Plataformas & Consola Virtual & Rol \\
\hline Aventura & Puzle & Lucha & Simulación \\
\hline Puzle & RPG & Otros & Otros \\
\hline \multirow[t]{9}{*}{ Plataformas } & Shooter & Puzle & \\
\hline & Simuladores & Shooter & \\
\hline & Velocidad & Xbox Live Arcade & \\
\hline & & Aventura & \\
\hline & & Deportes & \\
\hline & & Multijugador Online & \\
\hline & & PS Network & \\
\hline & & Realidad Virtual & \\
\hline & & Simulación & \\
\hline
\end{tabular}

Tabla 3. Clasificaciones en cuatro medios especializados en videojuegos en 2020

Vemos que la prensa tampoco emplea una clasificación única y también se mezclan criterios de clasificación. Es el caso de «Xbox Live Arcade», caracterizada por la plataforma, pero recogida como categoría junto a «Velocidad» (destreza puesta en marcha en esos juegos) o «Multijugador Online», clasificada según el número de jugadores, todas ellas categorías denominadas «Género» por la web Vandal. También hay categorías abiertas sin un criterio claro de clasificación, como «Otros» en 
HobbyConsolas y Vandal, o «Casual» en 3DJuegos. Asimismo, la terminología también difiere incluso referida a un mismo grupo («Rol» O «RPG», «Simulación» O «Simuladores», etc.).

Cabe señalar que estas clasificaciones, sin duda, resultan útiles a los redactores y especialistas en videojuegos, así como a los propios lectores, para situar ciertas características de los juegos sobre los que se habla y prever una lógica o esperar determinadas mecánicas en cada grupo. Sin embargo, al igual que sucede en el ámbito comercial, estas taxonomías no parecen responder a un criterio sistemático ni homogéneo.

\subsection{Propuestas académicas}

Algunas de las primeras clasificaciones de videojuegos, surgidas de los Game Studies y de los Estudios en Comunicación, fueron las de Crawford (1984), Levis (1997/2013), Wolf (2001/2005), King y Krzywinska (2002), Aarseth, Smedstad y Sunnanå (2003), Whalen (2004), Rollings y Adams (2003) y Apperley (2006). En el caso de Wolf o King y Krzywinska, ya se optó por priorizar el género interactivo -más próximo al enfoque ludológico- que otras cuestiones narrativas, aunque la mayoría de estas primeras aproximaciones recibieron críticas por no acomodarse a los géneros más modernos de la industria. Tal es la variedad de planteamientos que incluso existen obras, como la de López Redondo (2014), en las que se recogen y comparan diversas clasificaciones: las de Estallo (1995), Levis (1997/2013), Scholand (2002) y Newman (2004). Algunas categorizaciones más actuales en el ámbito de los Game Studies son las de Arsenault (2009), Clearwater (2011), Ensslin (2012) y Fencott et al. (2012).

En todas se dan circunstancias similares a las descritas en la industria: la evolución diacrónica es evidente e inevitable, dado el continuo desarrollo tecnológico, y la hibridación de géneros es cada vez más habitual. Asimismo, en muchas clasificaciones no se establecen categorías según un único criterio, sino que se mezclan varios, lo que resta sistematicidad. En algunas también se contempla la categoría "Otros» (Scholand, 2002), que, si bien da cuenta de todo aquel título que no pueda ubicarse en los demás grupos, representa una calificación demasiado ambigua que no recoge características comunes entre los videojuegos incluidos.

En el ámbito de la localización, contamos con las propuestas de O'Hagan y Mangiron (2013), Granell, Mangiron y Vidal (2015) y Méndez González y Calvo-Ferrer (2017). Las primeras, O’Hagan y Mangiron (2013), señalan la utilidad de los géneros para identificar convenciones textuales y tipos de textos que guíen a los traductores en la tarea, según el juego del que se trate y sus contenidos. La propuesta de O'Hagan y Mangiron se inclina en cierto modo hacia una concepción de género narrativo (Hatim y Mason, 1990; García Izquierdo, 2005), algo más cercano a la perspectiva lingüística que el concepto de género interactivo antes descrito (sección 2). Méndez González y Calvo-Ferrer, a su vez, se basan en las divisiones de la revista española MeriStation, especializada en videojuegos, y proponen una estrecha relación entre la localización y la prensa especializada que refleje las tendencias y usos del sector. 
No obstante, hasta la fecha, no conocemos una propuesta arraigada en el plano investigador que, por una parte, se ajuste a un criterio único de clasificación (lo cual permitiría contextualizar estudios empíricos de manera sistemática en distintos géneros interactivos) y que, además, sea extensible a otras áreas como la industria o la prensa especializada. Una taxonomía extendida tanto en investigación como en el ámbito profesional y comercial podría emplearse de manera práctica para estudios de diversa índole, como los de localización de videojuegos. Así, podrían establecerse comparaciones entre distintas categorías de videojuegos y explorar tendencias en la estrategia traductora a la hora de abordar la localización de cada categoría; o bien, examinar cuáles son los errores de traducción más frecuentes según las diferentes categorías, o dibujar un mapa de las preferencias de accesibilidad según géneros interactivos, entre muchas otras opciones que aún quedan por explorar empíricamente en localización.

\section{Los géneros interactivos: clasificaciones previas y propuesta}

Actualmente, parece indiscutible la calificación de texto audiovisual para los videojuegos, añadiendo, eso sí, la interactividad. Un videojuego puede concebirse como «un software, para distintos tipos de hardware, que genera un texto audiovisual [habitualmente] de entretenimiento y que permite la interacción del jugador o jugadores, y de estos entre sí, en el desarrollo de los acontecimientos a través de una pantalla y según unas reglas preestablecidas» (Mejías-Climent, 2019: 26). En esta definición, además del componente audiovisual, que es la base de todo videojuego, destaca una particularidad única e identificativa: la interacción (Mejías-Climent, 2017).

Una de las cuestiones que parece haberse obviado en los géneros de videojuegos es esta característica distintiva que los separa de cualquier otro producto audiovisual. Así, en línea con la propuesta del apartado 2, donde señalábamos la idoneidad de limitarnos a un único criterio para estructurar una taxonomía sistemática, coincidimos con el enfoque de Wolf (2005: 114-115), para quien la interacción, como diferenciadora de los videojuegos, desempeña el papel protagonista a la hora de clasificarlos:

In some ways, player participation is arguably the central determinant in describing and classifying video games, more so even than iconography. [...] Interactivity is an essential part of every game's structure and a more appropriate way of examining and defining video game genres. [...] Classification by iconography ignores the fundamental differences and similarities which are to be found in the player's experience of the game.

Su clasificación consta de 42 géneros interactivos (tabla 4) determinados por la gameplay, con la exclusión intencionada de otros elementos temáticos, pues su postura es la de emplear esta categorización en combinación con otros sistemas estilísticos (Clarke, Lee y Clark, 2017: 447). 


\begin{tabular}{|c|c|c|}
\hline Abstractos & Conducción & Puzles \\
\hline $\begin{array}{l}\text { Adaptación (de otros } \\
\text { medios) }\end{array}$ & Educativos & Concursos de preguntas \\
\hline Aventura & Huida & $\begin{array}{l}\text { Carreras (contra } \\
\text { oponentes) }\end{array}$ \\
\hline Vida artificial & $\begin{array}{l}\text { Lucha (personajes sin } \\
\text { armas) }\end{array}$ & De ritmo y baile \\
\hline Juegos de mesa & Vuelo & Juegos de rol \\
\hline $\begin{array}{c}\text { Captura } \\
\text { (objetos/personajes } \\
\text { que escapan) }\end{array}$ & Apuestas & Disparos shoot 'em up \\
\hline Juegos de cartas & Película interactiva & Simulación \\
\hline $\begin{array}{c}\text { Atrapar } \\
\text { (objetos/personajes } \\
\text { que no escapan } \\
\text { activamente) }\end{array}$ & $\begin{array}{c}\text { Simulación de la gestión } \\
\text { de recursos }\end{array}$ & Deportivos \\
\hline Persecución & Laberintos & Estrategia \\
\hline Recolección & Carreras de obstáculos & Juegos de tablero \\
\hline $\begin{array}{c}\text { Combate (dos o más } \\
\text { jugadores) }\end{array}$ & Juegos de papel y lápiz & Objetivo (apuntar) \\
\hline Demos & Pinball (simulación) & $\begin{array}{l}\text { Aventura gráfica (basados } \\
\text { principalmente en texto) }\end{array}$ \\
\hline Diagnóstico (del sistema) & Plataforma & $\begin{array}{l}\text { Simulación de } \\
\text { entrenamiento }\end{array}$ \\
\hline $\begin{array}{l}\text { Evasión (de proyectiles } \\
\text { u objetos en movimiento) }\end{array}$ & Juegos de programación & $\begin{array}{l}\text { Utilidad (propósito } \\
\text { funcional } \\
\text { más allá del } \\
\text { entretenimiento) }\end{array}$ \\
\hline
\end{tabular}

Tabla 4. Clasificaciones de videojuegos según Wolf (2005) (traducción propia)

Posteriormente, a partir de esta propuesta, Ensslin (2012) combinó algunos géneros similares y suprimió otros, para ajustar la clasificación de Wolf a la evolución de los videojuegos. Estas modificaciones se justifican de la siguiente manera, en palabras de Ensslin (2012: 44): 
Some of Wolf's original categories were grouped together as they are similar to each other. Some others (such as adaptation, demo, diagnostic, interactive movie, obstacle course, pencil-and-paper games, pinball, programming games, table-top games, target, text adventure, training simulation and utility) were omitted as they either do not (or no longer) constitute 'videogames' as such but rather peripheral materials, activities or other media, or are covered exhaustively by another category in the same typology. 'Adaptation' was omitted as it isn't a category based on player interaction but, thematically, on other texts, media and gaming activities. 'Adaptation games' tend to co-occur with most genres listed here.

Su trabajo recoge así estos 22 géneros interactivos de videojuegos:

\begin{tabular}{|c|c|}
\hline Juegos abstractos & Juegos de apuestas \\
\hline Aventuras & Simulación y gestión \\
\hline Vida artificial & Laberintos \\
\hline Juegos de persecución y captura & Carreras de obstáculos \\
\hline Juegos de recolección & Juegos de plataformas \\
\hline Juegos de combate y lucha & Puzles y concursos \\
\hline Juegos de esquivar & Juegos de ritmo y baile \\
\hline Juegos de conducción y carreras & Juegos de rol \\
\hline Juegos educativos & Juegos de disparos \\
\hline Juegos de evasión & Juegos de deportes \\
\hline Juegos de vuelo & Juegos de estrategia \\
\hline
\end{tabular}

Tabla 5. Clasificaciones de videojuegos según Ensslin (2012: 45-46) (traducción propia)

Estas propuestas, sin embargo, carecen de la necesaria conexión con la terminología actual, extendida entre usuarios y profesionales del sector. Además, Ensslin aún mantiene separados algunos géneros muy afines que podrían combinarse, como las tres categorías de juegos abstractos, laberintos y puzles. Asimismo, algunos grupos se prestan a revisar si el criterio de clasificación realmente ha sido el de la habilidad interactiva, como, por ejemplo, los juegos de «Vida artificial», en los que es difícil determinar cuál es la destreza en cuestión que debe activar el jugador.

Para suplir estas debilidades, recurrimos al trabajo de Fencott et al. (2012: 34), basado en grupos de actividades, es decir, diversas habilidades que han de poner en marcha los jugadores, agrupadas en los bloques de fighting, driving/riding, stunts/skills, strategy/tactics, gameplay/enhancement y narrative. Las 49 actividades distribuidas en cada una de estas categorías no se conciben como "géneros» de videojuegos, sino como las prácticas requeridas en ellos, es decir, el tipo de tareas y actividades que ejecuta el jugador.

La particularidad de esta propuesta es que estas destrezas se obtuvieron mediante un programa informático, GIL (Game Invader Live), desarrollado por los autores, cuyo 
objetivo es identificar las actividades que caracterizan a cada género de videojuegos y la relación que puede establecerse entre ellos. Alimentando este programa mediante un corpus de críticas en internet de videojuegos representativos de distintos géneros, hasta un total de 203 títulos (Fencott et al., 2012: 38-39), refinaron el listado de grupos de actividades y características de los 12 géneros que obtuvieron. Además de usar esta herramienta informática, partieron de la clasificación de Rollings y Adams (2003) en combinación con la terminología empleada con más frecuencia en la prensa especializada, de manera que su propuesta ya no resultara ajena al uso real de los jugadores. El resultado fue una clasificación de 12 géneros (tabla 6) según las destrezas que se requieren en cada grupo.

\begin{tabular}{|c|c|}
\hline Acción-aventura & Puzles \\
\hline Acción-shooter & Carreras \\
\hline Aventura & RPG (role-playing game) \\
\hline Beat-'em-up & Simulación \\
\hline Ritmo-acción & Deportes \\
\hline Plataformas & Estrategia \\
\hline
\end{tabular}

Tabla 6. Clasificaciones de videojuegos según Fencott et al. (2012: 38-39) (traducción propia)

\subsection{Propuesta de clasificación de géneros interactivos}

A partir de estos trabajos, cuyo criterio de clasificación es el género interactivo (el tipo de destrezas que emplea el jugador para activar el sentido completo del videojuego), ofrecemos una propuesta de 9 géneros interactivos (tabla 7). Tanto el ámbito académico, con fines investigadores, como la industria, la prensa especializada o los propios jugadores podrían encontrar útil una clasificación sucinta pero ampliable como la aquí propuesta, en la que cada género se identifica únicamente por las destrezas requeridas y, por tanto, facilita reconocer la lógica que subyace a las mecánicas del juego (Fencott et al., 2012: 21). En el caso de que surgieran nuevas destrezas con los avances tecnológicos, podrían añadirse más categorías; o bien, más subgéneros, si se dieran nuevas combinaciones de las destrezas ya contempladas.

Ha de reconocerse que toda clasificación se arriesga a cierta idealización, pues los videojuegos tienden cada vez más a mezclar destrezas (Ensslin, 2012: 43) y algunos géneros pueden mostrar solapamientos (Fencott et al., 2012: 42-43). No obstante, el interés de esta propuesta es partir de las destrezas principales empleadas en cada género interactivo a modo de etiqueta bajo la que agrupar una determinada combinación de diversas prácticas. El criterio exclusivo con el que se estructura nuestra clasificación, así, es el del género interactivo, aunque las etiquetas de los géneros no siempre se correspondan con el nombre de una única destreza, pero el aspecto que caracteriza cada categoría siempre será una o la combinación de varias destrezas. Algunos géneros 
se identifican por requerir una destreza más evidente, mientras que otros estarán diferenciados por la combinación de varias. A partir del género interactivo principal, la clasificación está abierta a la continua ampliación de los subgéneros que ya se proponen, para dar cabida a nuevas prácticas que puedan surgir, así como para añadir matices y ofrecer una mayor flexibilidad.

Al contar con solo nueve géneros interactivos, necesariamente, se han agrupado algunas de las categorías que ya proponían Wolf (2005) y Ensslin (2012), dada la afinidad de ciertos géneros. También se ha consultado en especial la clasificación de O'Hagan y Mangiron (2013) y se han tenido en cuenta las 49 actividades propuestas por Fencott et al. (2012) para caracterizar cada uno de los nueve géneros y sus correspondientes subgéneros, ya que esta terminología procede de la prensa especializada y, de tal modo, mantenemos la conexión con el uso real de los jugadores. Se trata, así, de una propuesta que puede resultar útil tanto en el plano académico como en la industria, al no recurrir a términos abstractos o novedosos, ajenos a los usuarios.

El criterio de clasificación del género interactivo -es decir, la mecánica de juego y el tipo de habilidades empleadas por el jugador- es exclusivo y, por tanto, diferenciador de los videojuegos frente a otros productos audiovisuales. En el caso particular de este trabajo, nos situamos en el plano investigador, concretamente, en la localización de videojuegos, que podría beneficiarse de una clasificación sistemática para delimitar las particularidades del enfoque o las estrategias de traducción de cada género interactivo (Jiménez-Crespo, 2013: 37), al igual que sucede con los géneros literarios o audiovisuales en los campos de la traducción literaria o audiovisual, respectivamente.

Partiendo del modelo de otras especialidades de traducción, los estudios empíricos y descriptivos en busca de tendencias, así como los estudios de recepción (Mangiron, 2018), podrían contribuir a dibujar un mapa de los rasgos compartidos y diferenciadores entre distintos géneros. En nuestro caso, el análisis de un género interactivo se limita a la búsqueda de tendencias en la traducción para doblaje -aunque podrían explorarse otras modalidades, como la subtitulación o la accesibilidad-. La intención así es situarnos en el paradigma de la Traducción Audiovisual y la metodología empleada en ella, como los Estudios Descriptivos en Traducción (EDT), y adaptarlos para dar cabida a otro producto audiovisual con una particularidad más, como ya señala Vázquez Rodríguez (2018: 37): «la TAV puede adaptarse y adoptar el estudio de la interactividad o la jugabilidad y la repercusión de ambas en la traducción de productos audiovisuales sin necesidad de [...] establecer un nuevo ámbito o paradigma de estudio totalmente nuevo». Así pues, una clasificación de géneros cinematográficos seguirá sus criterios estilísticos, iconográficos y narrativos para categorizar textos audiovisuales y sus particularidades de traducción, mientras que el análisis de videojuegos podría organizarse según una taxonomía propia, regida por la interactividad y las destrezas que esta demanda, aspecto diferenciador frente a los géneros cinematográficos o textuales. En otras palabras, según Adams (2009: 2), «[v]ideo game genres are determined by gameplay. what challenges face the player and what actions he takes to overcome those challenges». 


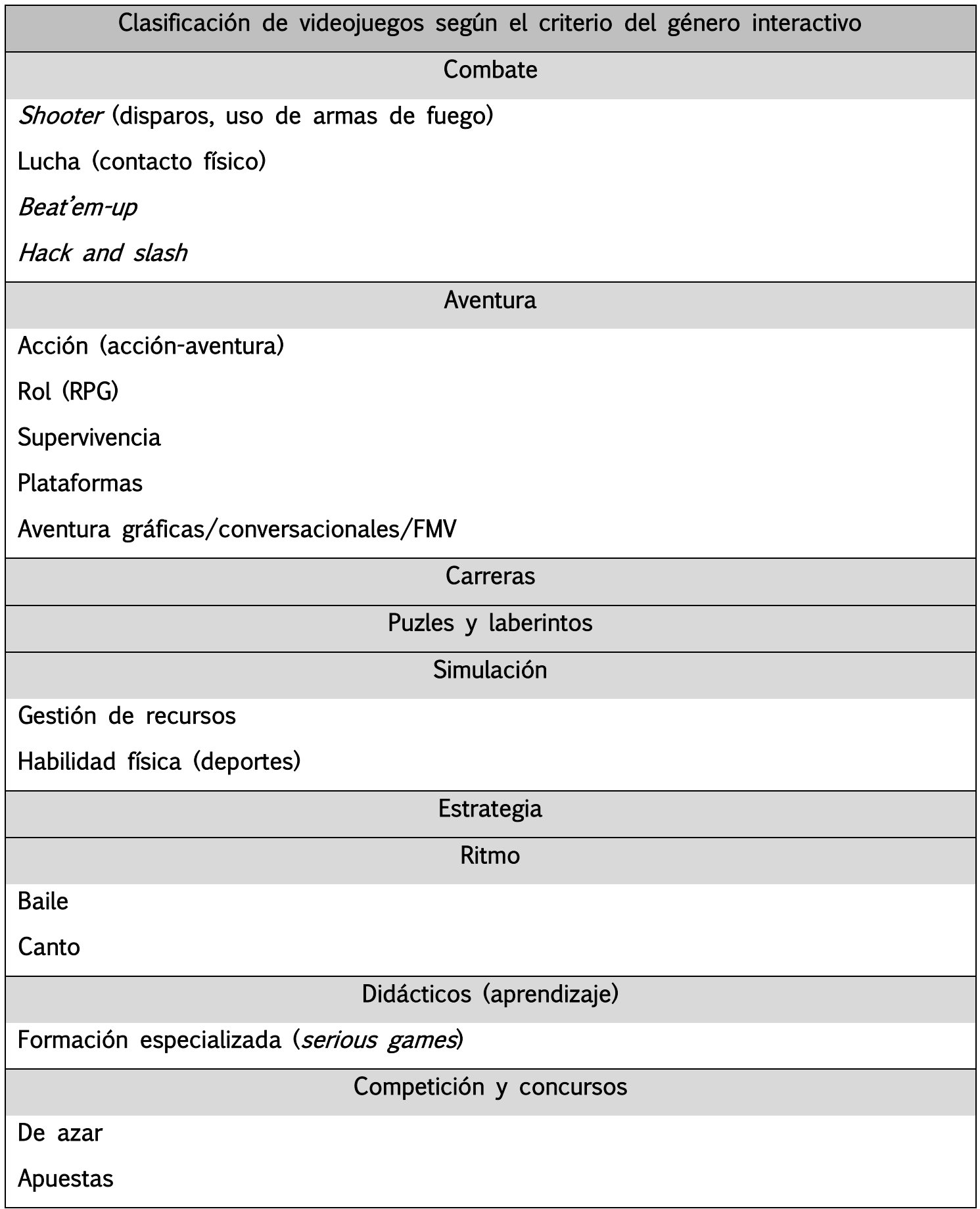

Tabla 7. Géneros interactivos de videojuegos

Con la elección del género interactivo como único criterio organizador, nos aseguramos de que todo título tenga cabida en esta propuesta, ya que la interactividad es algo inherente a este producto multimedia. Por el contrario, si creáramos una clasificación según el medio (entorno), sería imposible situar videojuegos completamente abstractos que carecen de similitud con los géneros cinematográficos o literarios; por ejemplo, Tetris (Alekséi Pázhitnov, 1984) o Edge (Mobigame, 2011). Como afirma Wolf (2005: 114), «[w]hile the ideas of iconography and theme may be appropriate tools for analyzing Hollywood films as well as many video games, another area, interactivity, is 
an essential part of every game's structure and a more appropriate way of examining and defining video game genres».

Tampoco sería práctico organizar videojuegos en función de la plataforma. Ciertamente es un criterio que siguen casi todas las empresas para estructurar los títulos que recogen en sus webs, por motivos prácticos para los usuarios, que necesitan saber si podrán jugar, dependiendo del hardware requerido. Sin embargo, hay muchas plataformas entre las que las versiones de los títulos no varían necesariamente, como las consolas y los ordenadores (a excepción de los juegos para aplicaciones móviles o small device [Jiménez-Crespo, 2013], que suelen ser algo más reducidos). Además, la plataforma no representa una característica inherente a la configuración del juego, sino externa a él, y determina modificaciones técnicas de compatibilidad, no necesariamente de localización (salvo en cuanto a terminología de botones y comandos y algunas diferencias en las restricciones de espacio y la inclusión de audio). Por tanto, no constituye un rasgo propio del texto audiovisual interactivo que parezca justificar una propuesta de clasificación útil para la investigación empírica.

El modo de juego (perspectiva y número de jugadores) sería un criterio de clasificación que obligaría a crear categorías demasiado amplias y heterogéneas, ya que títulos tan dispares como Splatoon (Nintendo, 2015) o Grand Theft Auto V (Rockstar Games, 2013) se situarían en el mismo grupo de juegos en tercera persona, pero las destrezas requeridas en ellos son diferentes. Por tanto, una clasificación con grupos tan extensos no permitiría la sistematización de estudios caracterizadores de cada grupo si estos grupos no tienen rasgos homogéneos compartidos. También se da el mismo inconveniente que si clasificáramos según el medio: no todos los videojuegos ofrecen el control de un personaje que pueda apreciarse desde una perspectiva u otra, sino que existen casos de manejo de objetos o situaciones que hacen imposible catalogar el título según la perspectiva desde la que se aprecia, como Candy Crush (King, 2012) o RUSH (Two Tribes, 2010).

Clarke, Lee y Clark (2017) recogen algunas críticas que se han hecho a otras clasificaciones anteriores, como la desconexión con la terminología real de los usuarios (aspecto que ya se ha justificado para nuestra propuesta), la inestabilidad de los géneros con la evolución de los videojuegos, la falta de identificación de los rasgos de cada categoría, la limitación creativa que una taxonomía cerrada establece y la imposibilidad de situar algunos títulos en ningún grupo.

La inestabilidad de los géneros puede superarse en la propuesta anterior añadiendo tantas categorías y subcategorías como destrezas nuevas surjan en el entorno de los videojuegos, pues no se trata de una clasificación cerrada e inamovible. Los rasgos de cada categoría son claros pero flexibles, ya que cada una se caracteriza por requerir una o varias destrezas y pueden añadirse nuevas combinaciones. La limitación creativa puede suponer un punto débil en clasificaciones empleadas en el ámbito de los Game Studies o del desarrollo de videojuegos, pero no debe olvidarse que la propuesta que aquí ofrecemos busca principalmente una aplicación práctica en la sistematización de estudios empíricos. Por último, consideramos que cualquier videojuego puede ubicarse 
en la tabla anterior, dado que el criterio de la interactividad (las destrezas requeridas) es un requisito común que todo videojuego presenta.

Antes de exponer qué destrezas caracterizan cada género, abordemos un caso práctico para ejemplificar el uso de esta clasificación: en Mejías-Climent (2019) se emplean los géneros interactivos para estructurar un estudio empírico y descriptivo sobre el ajuste del doblaje en videojuegos de acción-aventura. El objetivo de esta clasificación fue delimitar el corpus de análisis para situarlo dentro de una categoría con rasgos definitorios y diferenciados de productos no interactivos, en los que se pudieran identificar tendencias en la aplicación de las sincronías del doblaje (Mejías-Climent, 2017). Partiendo de una población de 106 videojuegos comercializados en España entre 2015 y 2016 con los diálogos sonoros en español, se delimitó el catálogo a 80 títulos que, además, fueran considerados triple A (de elevado presupuesto) y partieran originalmente de un desarrollo en inglés.

En este punto, se recurrió al género interactivo para obtener un amplio listado de videojuegos que compartían la característica de requerir la combinación de destrezas propia de los juegos de acción-aventura. Al tratarse de una gran variedad de títulos, se aplicó un nuevo filtro, el del medio (entorno), de manera que se excluyeran medios fantásticos o que no permitieran el análisis de diálogos humanos. El siguiente filtro aplicado fue el de la plataforma, pues el corpus debía componerse de videojuegos para ordenador, por motivos de disponibilidad. A continuación, se cribó el listado según el modo, para descartar todo juego que no se jugara en tercera persona o que permitiera el modo multijugador. Por último, se optó por títulos desarrollados y localizados por empresas diferentes, para asegurar una variedad de prácticas profesionales sobre las que identificar tendencias. Así, el corpus se limitó a tres títulos sobre los que se detectaron ciertos patrones en el uso de las sincronías de doblaje.

Los patrones identificados en estos doblajes parecen responder en cierta medida a las características de los juegos de acción-aventura situados en un medio realista: los momentos narrativos, cuya configuración visual no depende del jugado (cinemáticas), tienden a preferir un ajuste más estricto en el doblaje, mientras que los momentos de plena interacción o interacción limitada (acción de juego y diálogos) suelen recurrir a niveles de ajuste del doblaje más relajados. Dadas las limitaciones de espacio, nos remitimos a Mejías-Climent (2019) para una explicación pormenorizada de estas tendencias que pueden asociarse, en los juegos analizados, a este género interactivo de acción-aventura limitado a un entorno realista.

Estos fueron los requisitos necesarios para la citada investigación, pero, al aplicar el filtro del medio o entorno estilístico-narrativo donde se desarrolle el juego, podría optarse por multitud de etiquetas con las que delimitar y completar la caracterización de los juegos que interese analizar con un objetivo determinado. Por ejemplo, podrían buscarse tendencias en el doblaje o la subtitulación de videojuegos también de acciónaventura, pero que se desarrollen en un medio histórico, bélico, cómico o fantástico. Así, la utilidad de nuestra propuesta establece como criterio inicial de organización la interactividad, las destrezas que requieren los juegos, como aspecto diferenciador de películas o series. Pero, una vez seleccionado el género interactivo, podrán aplicarse 
tantos filtros (criterios) como los objetivos de la investigación planteen, según otras convenciones que quieran analizarse.

\subsection{Los nueve géneros interactivos}

Para delimitar los géneros interactivos propuestos, repasemos las principales características contempladas en las nueve categorías. Debe recordarse que se trata de etiquetas para los géneros interactivos, que pueden desglosarse en tantos subgéneros como su evolución tecnológica requiera, siempre tomando como criterio de clasificación el tipo de destrezas y habilidades que se emplean en cada categoría, independientemente del medio narrativo en el que se sitúen, el modo de juego o la plataforma en la que se jueguen. Asimismo, nos limitamos a describir sus características en cuanto al género interactivo, pero las tendencias de traducción que puedan asociarse a cada género aún están por explorar, dado que se necesitan datos empíricos y descriptivos para extraer tendencias en el doblaje de videojuegos (como ejemplifica el estudio de Mejías-Climent, 2019), en su subtitulación, en la accesibilidad o en la estrategia global de traducción, por nombrar solo algunas posibilidades de investigación que nos brinda una clasificación sistemática (Mangiron, 2017).

En primer lugar, los videojuegos de combate se centran en acabar con el enemigo, con armas o luchando cuerpo a cuerpo. Por tanto, deben emplearse las destrezas de fuerza y resistencia del personaje, ataque y defensa, captura, confrontación, persecución y uso de armas, y son importantes unos buenos reflejos al atacar y defenderse. Se especifican en esta categoría los subgéneros de disparos (shooters), donde habrán de manejarse armas de fuego, y los de lucha, mediante el contacto físico entre el jugador y otros personajes o jugadores, bien con armas afiladas (hack'n'slash) o bien, cuerpo a cuerpo, enfrentándose a un continuo e ingente número de enemigos (beat'em up).

La segunda categoría son los videojuegos de aventura. Estos parecen ser los más variados en lo que a destrezas se refiere $y$, de hecho, se caracterizan por precisar de una combinación de varias, principalmente, «la exploración, la investigación, la resolución de puzles, la interacción con personajes y el avance manera lineal, centrado en la trama del juego» (Turnes, 2020). Son juegos que implican una actividad incesante y exploratoria. El jugador encarna la piel de uno o varios personajes, persiguiendo un determinado fin que suele presentarse al comienzo, según un trasfondo narrativo. Para lograrlo, han de superarse impedimentos que implican destrezas combinadas como la rapidez, la agilidad de movimiento con el periférico, la toma de decisiones, el análisis de pistas o la resolución de puzles y enigmas. Al contar con una motivación narrativa, la elección de un medio determinado, en combinación con el género interactivo de la acción-aventura, puede generar corpus de análisis con unas características muy concretas; por ejemplo, aventuras de supervivencia en un medio de terror, juegos de rol fantásticos, acciónaventura histórica, etc.

En los juegos de aventura se han incluido varias subcategorías, como la acciónaventura, que implica una actividad dinámica continua, exploradora y defensiva, en busca de la consecución del objetivo principal; los juegos de rol, en los que la caracterización del personaje que se encarne determinará las destrezas implicadas; los de supervivencia, 
en donde destacarán la rapidez y la agilidad evasivas y defensivas; los de plataformas, en los que el movimiento acrobático será característico, y las aventuras gráficas, conversacionales (con interacción principalmente textual) o los antiguos videojuegos de movimiento completo (FMV o full motion video). En ellos, la toma de decisiones será la tónica principal, a partir de la capacidad de deducción, análisis y valoración de la narración, transmitida principalmente mediante un nutrido número de cinemáticas.

Los videojuegos de carreras implican rapidez, coordinación, concentración y agilidad en el uso de periféricos, ya sea mediante velocidad o esquivando obstáculos con automóviles u otros medios de transporte reales o imaginarios, o montando animales, con el propósito de alcanzar la meta en primer lugar o batir récords.

Los puzles y laberintos suelen asociarse a un pensamiento abstracto, matemático o espacial y, en ocasiones, creativo o razonado. Suele ser necesario manipular con destreza objetos o piezas y manejar colores y formas geométricas. También es necesario un uso ágil de los controles en el caso de tener que encajar o manipular objetos virtuales.

La simulación busca una plena inmersión en el entorno real que se reproduce. Se asocia con la capacidad de gestión de recursos de diversa índole (transportes, economía, comercio, edificación...), con el razonamiento o habilidad, o con los conocimientos deportivos. Puede ser necesaria la capacidad resolutiva o la visión de conjunto, y también la rapidez y el equilibrio, en algunos juegos de deportes.

Los videojuegos de estrategia, normalmente, precisan de concentración y capacidad táctica y analítica. La rapidez mental y la reacción ágil también son básicas si se trata de estrategia en tiempo real, en lugar de por turnos.

Los videojuegos de ritmo se asocian con habilidades musicales, de entonación o de capacidad corporal rítmica y dinámica. También con la agilidad en el uso del periférico si este se emplea reproduciendo algún instrumento musical. En tal caso, pueden asemejarse a los de simulación, aunque la destreza principal puesta en práctica será la musical.

Aunque, inicialmente, los juegos didácticos puedan considerarse una categoría transversal (otros géneros interactivos pueden incluir fines didácticos), la particularidad de los videojuegos didácticos es que tienden a requerir una actividad mental más elevada, tanto matemática como geométrica, lingüística o reflexiva, de razonamiento, análisis y memoria, en función de los contenidos y las edades a las que se dirijan, y su principal objetivo es la estimulación de varias destrezas cognitivas con fines didácticos. También pueden encontrarse en esta categoría algunos juegos serios, diseñados con fines específicos distintos del puro entretenimiento (O’Hagan y Mangiron, 2013).

Los videojuegos de competición suelen albergar un alto grado de azar y destrezas variadas, en especial, la velocidad, el razonamiento y el manejo ágil de la cultura general, en caso de tratarse de concursos de preguntas. 


\section{Conclusiones}

Como ya señalaban O'Hagan y Mangiron (2013: 66), «[a] wide variety of games are published today and the variation even within the same genre makes a completely standardized approach to game localization difficult, as has frequently been pointed out by industry sources». Al emprender estudios empíricos en videojuegos, bien desde una perspectiva exclusivamente lingüística, o bien, cultural o interdisciplinar, la amplia variedad de títulos que inundan el prolífico mercado actual dificulta enormemente la clasificación de este producto audiovisual interactivo en una serie de géneros identificables y con características comunes y reconocidas, así como propias de los videojuegos.

El objetivo de este artículo, así, ha sido recorrer brevemente la evolución de las distintas posturas sobre la clasificación de videojuegos en varios ámbitos, tanto en la investigación como en la industria, para ofrecer, a partir del análisis teórico, una propuesta práctica y útil para clasificar videojuegos con fines investigadores, en especial, en el campo de la localización y los EDT, aunque podría emplearse en cualquier otro análisis sistemático de videojuegos, procurando que se alinee con el uso habitual y la terminología de la prensa especializada y los videojugadores y, por tanto, también aspire a ser de utilidad para ellos.

La propuesta se restringe a un único criterio de clasificación, el del género interactivo (Wolf, 2005), es decir, el tipo de destrezas que ha de activar el jugador para generar interacción. El motivo de elección de este único criterio es que se trata del aspecto distintivo de los videojuegos frente a otros productos audiovisuales no interactivos, cuyos géneros se refieren a convenciones narrativas y estilísticas relativamente asentadas, pero que nunca contemplan la dimensión interactiva. Otros criterios de clasificación de videojuegos, como el medio (entorno), el modo o la plataforma pueden complementar ( $y$, de hecho, es recomendable que lo hagan) las nueve categorías de géneros interactivos descritos aquí, de forma que puedan limitarse corpus más o menos caracterizados, en función del fenómeno en cuestión que quiera analizarse. Como muestra del uso práctico de esta taxonomía propuesta, se ha expuesto sucintamente el análisis empírico del doblaje de videojuegos de acción-aventura (Mejías-Climent, 2019), cuyo corpus podría extenderse a otros géneros o subgéneros, con la intención de trazar un mapa de las tendencias de traducción en el doblaje de videojuegos, así como en otras modalidades de traducción audiovisual o estrategias localizadoras.

Esta propuesta se mantiene flexible al dinámico panorama de los videojuegos actuales, cuyas desarrolladoras mezclan y combinan géneros continuamente para dotar de originalidad a sus productos. Por ello, a partir de las nueve categorías enumeradas, se proponen algunos subgéneros interactivos y se mantiene abierta la adición de otros géneros y subgéneros nuevos, según puedan surgir nuevas opciones de interacción y habilidad requeridas por el jugador.

Una taxonomía sistemática, pero flexible y ampliable, que pueda ser útil para la investigación, la industria y los propios consumidores supone un valor añadido al campo de los videojuegos, para facilitar su catalogación y las características de cada género, diferenciados además de otros productos audiovisuales o literarios, pues esta taxonomía 
se deriva además de la particularidad interactiva de los videojuegos. Asimismo, puede contribuir a diseñar un mapa de los géneros interactivos de videojuegos en el que se estructuren diversas preferencias y expectativas de los usuarios, tanto en el plano localizador como en las características del propio diseño, al igual que ya existen clasificaciones que la sociedad identifica tácitamente en el mundo audiovisual o literario. En el más reciente ámbito de los videojuegos también esta identificación tácita puede contribuir al avance de la disciplina y a la caracterización por géneros de las prácticas localizadoras (Jiménez-Crespo, 2013).

\section{Referencias}

3DJuegos (2021). Todos los Juegos. 〈https://www.3djuegos.com/novedades/juegosgeneros/juegos/OfOfOf0/juegos-populares/〉. [Accessed: 20211223].

Aarseth, Espen; Smedstad Solveig, Marie; Sunnanå, Lise (2003). A multidimensional typology of games. In: Proceedings of the 2003 DiGRA International Conference: Level Up. 〈http://www.digra.org/wp-content/uploads/digital-library/05163.52481.pdf〉. [Accessed: 20211223].

Adams, Ernest (2009). The Designer's Notebook: Sorting Out the Genre Muddle. Gamasutra (July, 9). 〈https://www.gamasutra.com/view/feature/4074〉. [Accessed: 20211223].

Agost, Rosa (1999). Traducción y doblaje: palabras, voces e imágenes. Barcelona: Ariel. (Ariel practicum).

Apperley, Thomas H. (2006). Genre and Game Studies: Toward a critical approach to video game genres. Simulation and Gaming, v. 37, n. 1.

〈https://doi.org/10.1177/1046878105282278〉. [Accessed: 20211223].

Arsenault, Dominic (2009). Video Game Genre, Evolution and Innovation. Eludamos: Journal for Computer Game Culture, v. 3, n. 2. 〈https://www.eludamos.org/index.php/eludamos/article/view/vol3no2-3/125〉. [Accessed: 20211223].

Bermejo Bermejo, Jordi (2013). El videojuego: Cibertexto y Cajón de arena. In: XVIII Simposio de la SELGYC, 9-11 de septiembre 2010. Alicante: Bilioteca Virtual Miguel de Cervantes. 〈http://www.cervantesvirtual.com/obra/el-video-juego--cibertexto-ycajon-de-arena/>. [Accessed: 20211223].

Bogost, lan (2007). Persuasive Games: the expressive power of videogames. Cambridge, Mass: MIT Press.

Chaume, Frederic. (2003). Doblatge i subtitulació per a la TV. Vic: Eumo; Barcelona: Facultat de Traducció i Interpretació de la UPF. (Biblioteca de traducción i interpretación; 8).

Clarke, Rachel Ivy; Lee, Jin Ha; Clark, Neils (2017). Why Video Game Genres Fail: A Classificatory Analysis. Games and Culture, v. 12, n. 5. 〈https://doi.org/10.1177/1555412015591900〉. [Accessed: 20211223]. 
Clearwater, David A. (2011). What Defines Video Game Genre?: Thinking about Genre Study after the Great Divide. Loading: The Journal of the Canadian Game Studies Association, v. 5, n. 8, pp. 29-49. 〈https://journals.sfu.ca/loading/index.php/loading/article/view/67〉 [Accessed: 20211223].

Crawford, Chris. (1984). The art of computer game design. Berkeley: McGraw-Hill.

EA Games (2021). Juegos. 〈https://www.ea.com/es-es/games/library〉. [Accessed: 20211223].

Ensslin, Astrid (2012). The Language of Gaming. Nueva York: Palgrave Macmillan.

Estallo, Juan Alberto (1995). Los videojuegos: juicios y prejuicios. Barcelona: Planeta. (Manuales prácticos).

Fencott, Clive; et al. (2012). Game Invaders: The Theory and Understanding of Computer Games. Hoboken, Nueva Jersey: John Wiley.

Frasca, Gonzalo (2001). Rethinking agency and immersion: video games as a means of consciousness-raising. Digital Creativity, v. 12, n. 3, pp. 167-174. 〈https://www.ctcs505.com/wp-content/uploads/2016/01/Frasca-agency-3.pdf〉. [Accessed: 20211223].

Frasca, Gonzalo. (2003). Simulation versus Narrative: Introduction to Ludology. In: Wolf, Mark J. P.; Perron, Bernard (eds.). The Video Game Theory Reader. New York; London: Routledge.

García Izquierdo, Isabel (ed.). (2005). El Género textual y la traducción: reflexiones teóricas y aplicaciones pedagógicas. Bern: Peter Lang.

Granell, Ximo; Mangiron, Carme; Vidal, Núria (2015). La traducción de videojuegos: nuevas tendencias en traducción y comunicación multimedia Sevilla: Bienza.

Hatim, Basil; Mason, Ian (1990). Discourse and The Translator. London; New York: Longman.

Hobby Consolas (2021). Lista de los mejores juegos. 〈https://www.hobbyconsolas.com/videojuegos/top-juegos〉. [Accessed: 20201223].

Hurtado Albir, Amparo (2011). Traducción y Traductología: introducción a la traductología. $5^{a}$ ed. rev. Madrid: Cátedra.

Jiménez-Crespo, Miguel Ángel (2013). Translation and web localization. Milton Park, Abingdon, Oxon: Routledge.

King, Geoff; Krzywinska, Tanya. (2002). Screenplay: Cinema, videogames, interfaces. London; New York: Wallflower.

Levis-Czernik, Diego S. (2013). Los videojuegos: un fenómeno de masas: 2. ${ }^{\text {a }}$ ed. Barcelona: Paidós.

López Redondo, Isaac (2014). ¿Qué es un videojuego?: claves para entender el mayor fenómeno cultural del siglo XXI. Sevilla: Arcade. 
López Redondo, Isaac; Aramburú Moncada, Luisa Graciela (2020). El tratamiento del videojuego como producto cultural en la prensa especializada en España: un estudio de caso: Manual. Textual \& Visual Media, n. 13. $\langle$ https://textualvisualmedia.com/index.php/txtvmedia/article/view/233〉. [Accessed: 20211223].

Mangiron, Carme (2018). Game on! Burning Issues in Game Localisation. Jat: Journal of Audiovisual Translation, v. 1, n. 1. 〈https://doi.org/10.47476/jat.v1i1.48〉. [Accessed: 20211223]

Mejías-Climent, Laura (2018). Multimodality and dubbing in video games: A research approach. Linguistica Antverpiensia, New Series: Themes in Translation Studies, v. 17, pp. 99-113. 〈https://doi.org/10.52034/lanstts.v17i0.463〉 [Accessed: 20211223].

Mejías-Climent, Laura (2018). Synchronization in Video Games: The Dubbing of Assassin's Creed Syndicate. Trans: revista de Traductología, n. 22 (diciembre), pp. 11-30. 〈https://doi.org/10.24310/trans.2018.v1i22.2966〉. [Accessed: 20211223].

Mejías-Climent, Laura (2019). La sincronización en el doblaje de videojuegos. Análisis empírico y descriptivo de los videojuegos de acción-aventura. Tesis doctoral. Universitat Jaume I. Alacant. 〈http://dx.doi.org/10.6035/14110.2019.567953〉. [Accessed: 20211223].

Méndez González, Ramon; Calvo-Ferrer, José Ramon (2017). Videojuegos y Iparaltraducción: aproximación a la práctica localizadora. Albolote, Granada: Comares.

Meristation (2020). Listado de Juegos. 〈https://as.com/meristation/juegos/〉. [Accessed: 20200416].

Newman, James A. (2004). Videogames. London; New York: Routledge. (Routledge introductions to media and communications).

Nintendo (2020). [Nintendo website]. 〈https://www.nintendo.es/Buscar/Buscar299117.html?q=\&faf=GAME $>$. [Accessed: 20200416].

Nord, Christiane (2018). Translating as a Purposeful activity: Functionalist Approaches Explained. $2^{\text {nd }}$ ed. Oxon, Nueva York: Routledge.

O’Hagan, Minako (2007). Video games as a new domain for translation research: From translating text to translating experience. RevistaTradumàtica: traducció i tecnologies de la informació i la comunicació n. 5, pp. 1-6. 〈http://www.fti.uab.es/tradumatica/revista/num5/articles/09/09.pdf〉. [Accessed: 20211223].

O'Hagan, Minako; Mangiron, Carme (2013). Game localization: translating for the global digital entertainment industry. Amsterdam: John Benjamins. (Benjamin's translation library).

Origin (2020). [Origin website]. 〈https://www.origin.com/esp/es-es/store/>. [Accessed: 20200416]. 
Rollings, Andrew; Adams, Ernest. (2003). Andrew Rollings and Ernest Adams on game design. $1^{\text {st }}$ ed. Berkeley: New Riders.

Scholand, Michael (2002). Localización de videojuegos. RevistaTradumàtica: traducció i tecnologies de la informació i la comunicació n. 1, pp. 1-9 〈http://www.fti.uab.es/tradumatica/revista〉. [Accessed: 20211223].

Steam (2020). [Steam website]. 〈https://store.steampowered.com/〉. [Accessed: 20200416].

Turnes, Y. (2020). Aventura. GamerDic. 〈http://www.gamerdic.es/termino/aventura〉. [Accessed: 20200417].

Ubisoft Store (2020). Género. 〈https://store.ubi.com/es/game-genre〉. [Accessed: 20210416].

Vandal (2020). Ránking de los mejores videojuegos. 〈https://vandal.elespanol.com/rankings/videojuegos〉. [Accessed: 20200404].

Vela Valido, J. (2005). Localización de videojuegos. In: Reineke, Detlef (dir.) Traducción y localización: mercado, gestión y tecnologías. Las Palmas de Gran Canaria: Anroart.

Whalen, Zach (2004). Game/Genre: A Critique of Generic Formulas in Video Games in the Context of The Real. Works and Days 43/44, v. 22, n. $1 \& 2$. $\langle$ http://worksanddays.net/2004/File29.Whalen_File29.Whalen.pdf〉. [Accessed: 20211223].

Wijman, Tom (2020). The World's 2.7 Billion Gamers Will Spend \$159.3 Billion on Games in 2020; The Market Will Surpass $\$ 200$ Billion by 2023. Newzoo. <https://newzoo.com/insights/articles/newzoo-games-market-numbers-revenues-andaudience-2020-2023/>. [Accessed: 20211110].

Wolf, Mark. J. P. (ed.) (2005). The Medium of the Video Game. 3rd ed. Austin: The University of Texas Press. 